\title{
PENGARUH MUROTTAL AL-QUR'AN TERHADAP INTENSITAS NYERI PADA PASIEN POST OPERASI SECTIO CAESAREA
}

\author{
Khairun Nuhan*, Titi Astuti*, Al Murhan* \\ *Jurusan Keperawatan Poltekkes Tanjungkarang
}

\begin{abstract}
Prevalensi persalinan sectio caesarea di Indonesia menurut WHO pada tahun 2015 adalah 15,3\%. Pada pasien post operasi sectio caesarea setelah anestesi menghilang pasien akan merasakan nyeri, sehingga diperlukan terapi yang efektif dan aman dari efek samping. Terapi Al-Qur'an salah satu bentuk teknik distraksi (pengalihan) secara non farmakologi untuk menurunkan intensitas nyeri yang dirasakan. Keberhasilan menggunakan murrotal $70 \%$ dari penelitian terkait. Penelitian ini menggunakan desain quasi exsperiment dengan pendekatan nonrandomized control grup pretest postests design. Teknik pengambilan sampel dengan menggunakan teknik accidental sampling sebanyak 22 responden (11 responden kelompok perlakuan dan 11 responden kelompok kontrol). Pengumpulan data nyeri menggunakan instrumen Numeric Rating Scale (NRS). Uji statistik menggunakan Wilcoxon dan MannWithney. Hasil penelitian terdapat perbedaan pengaruh terapi murottal Al-Qur'an terhadap penurunan intensitas nyeri pada pasien post operasi SC pada kelompok perlakuan dan kelompok kontrol p-value 0.001. Peneliti menyarankan agar pihak RS mempertimbangkan menggunakan terapi komplementer murottal Al-Qur'an untuk mempersiapkan ibu menghadapi operasi SC menggunakan SOP yang ada.
\end{abstract}

Kata Kunci: Nyeri, Post SC, Terapi Murottal Al-Qur'an

\section{LATAR BELAKANG}

Menurut World Health Organization (WHO), standar rata-rata Sectio Caesarea (SC) adalah sekitar $5-15 \%$ per 1.000 kelahiran di dunia. Rumah sakit pemerintahan kira-kira $11 \%$ sementara di rumah sakit swasta bisa lebih dari $30 \%$. peningkatan persalinan dengan Sectio Caesarea (SC) di seluruh Negara selama tahun 2007-2008 yaitu 110.000 per kelahiran di seluruh Asia (Gibbson L. et all, 2010 dalam Sumelung, Kundre, dan Karundeng, 2014: 2). Survei Global Kesehatan oleh WHO (2013)yang dituliskan dalam data statistik kesehatan dunia menyebutkan bahwa angka kejadian SC terbesar terdapat pada wilayah Amerika (36\%), wilayah Western Pasifik (24\%) dan wilayah Eropa (23\%). Data statistik WHO (2013) juga menyebutkan bahwa negara tertinggi dengan kejadian SC terdapat pada negara Brazil (52\%), Cyprus (51\%), Mexico (39\%).

WHO tahun 2015 selama hampir 30 tahun tingkat persalinan dengan SC menjadi $10 \%$ sampai $15 \%$ dari semua proses persalinan di Negara-negara berkembang. RISKESDAS tahun 2013 tingkat pesalinan sectio caesarea di Indonesia sudah melewati batas maksimal standar WHO 5-15\%. Tingkat persalinan sectio caesarea di Indonesia 15,3\% sampel dari 20.591 ibu yang melahirkan dalam kurun waktu 5 tahun terakhir yang di survey dari 33 provinsi. Gambaran adanya faktor resiko ibu saat melahirkan atau di operasi caesarea adalah 13,4\% karena ketuban pecah dini, 5,49\% karena Preeklampsia, 5,14\% karena Perdarahan, 4,40\% Kelainan letak Janin, 4,25\% karena jalan lahir tertutup, 2,3\% karena rupture uteri (Kemenkes, 2014).

Tindakan operasi menyebabkan terjadinya perubahan kontinuitas jaringan tubuh. Pada proses operasi digunakan anastesi agar pasien tidak merasakan nyeri pada saat dibedah. Namun setelah operasi selesai dan pasien mulai sadar, ia akan merasakan nyeri pada bagian tubuh yang mengalami pembedahan. Nyeri yang dirasakan ibu post operasi Sectio Caesarea berasal dari luka yang terdapat dari perut (Sjamsuhidajat, 2005). Tidak 
ada dua individu mengalami nyeri yang sama dan tidak ada dua kejadian nyeri yang sama menghasilkan sensasi nyeri atau respon nyeri yang identik sama pada seorang individu karena nyeri bersifat subjektif (Perry \& Potter, 2010). Salah satu gejala yang paling sedikit dipahami padahal nyeri merupakan gejala yang paling sering terjadi di bidang medis, oleh karena itu peran perawat sangat diperlukan untuk membantu klien dan anggota keluarga dalam upaya mengatasi nyeri. Penting juga perawat memahami makna nyeri secara holistik pada setiap individu sehingga dapat mengembangkan strategi penatalaksanaan nyeri selain pemberian analgetik yaitu terapi non farmakologi.

Penatalaksanaan nyeri di bagi menjadi dua yaitu dengan farmakologi dan nonfarmakologi. Penatalaksanaan nonfarmakologis terdiri dari berbagai tindakan mencakup intervensi perilaku dan kognitif menggunakan agen-agen fisik meliputi stimulus kulit, stimulus elektrik saraf kulit (transcutaneous electrical nerve stimulation/ TENS), akupuntur dan pemberian placebo. Intervensi prilaku kognitif meliputi tindakan distraksi, tehnik relaksasi, imajinasi terbimbing, umpan balik biologis (biofeedback), hypnosis dan sentuhan terapeutik (Potter \& Perry, 2006).Teknik distraksi sangat efektif digunakan untuk mengalihkan nyeri, hal ini disebabkan karena distraksi merupakan metode dalam upaya untuk mengurangi nyeri dan sering membuat pasien lebih menahan nyerinya. Salah satu teknik distraksi yang efektif adalah terapi murrotal Al-Qur'an, yang dapat menurunkan nyeri fisiologis, stress, dan kecemasan dengan mengalihkan perhatian seseorang dari nyeri (Potter \&Perry, 2006). Murrotal yang di gunakan memakai Surah Al-Kahf beserta terjemahnya yang berisi 110 ayat karena dapat memberikan ketenangan dan menurunkan rasa nyeri (Elzaky: 2014). Hal ini telah dibuktikan oleh berbagai ahli seperti yang telah dilakukan Ahmad Al Khadi direktur utama Islamic Medicine Institute for Education and Research di Florida, Amerika Serikat. Dalam konferensi tahunan ke XVII Ikatan
Dokter Amerika, dengan hasil penelitian bahwa mendengarkan ayat suci Al-Quran memiliki pengaruh yang signifikan dalam menurunkan ketegangan urat saraf reflektif dan hasil ini tercatat dan terukur secara kuantitatif dan kualitatif oleh alat berbasis komputer (Remolda, 2009). Musik (murrotal Al-Qur'an) yang dapat menurunkan nyeri fisiologis, stress, dan kecemasan dengan mengalihkan perhatian seseorang dari nyeri. Murrotal Al-Qur'an terbukti menunjukkan efek yaitu menurunkan frekuensi denyut jantung, mengurangi kecemasan dan depresi, menghilangkan nyeri menurunkan tekanan darah, dan mengubah persepsi waktu (Elzaky, 2014). Murrotal menghasilkan perubahan status kesadaran melalui bunyi, kesunyian, ruang dan waktu. Murrotal harus didengar minimal 15 menit supaya dapat memberikan hasil efek terapeutik. Di keadaan perawatan akut, mendengarkan murrotal dapat memberikan hasil yang sangat efektif dalam upaya mengurangi nyeri pasca operasi klien (Potter \&Perry, 2006). Tetapi pada kenyataannya, masih sedikit rumah sakit yang menggunakan metode nonfarmakologi dalam penatalaksanaan nyeri salah satunya terapi murrotal. Mereka lebih menitikberatkan penatalaksanaan nyeri dengan metode farmakologis salah satunya pemberian analgetik terutama pada pasien pasca operasi (www.ipmg-online.com edisi 7 September 2011). Seperti yang kita ketahui bahwa pemberian analgetik secara berkelanjutan, tidak sesuai dengn aturan dan monitor yang tepat akan menimbulkan ketergantungan (Sulistyo, 2012).

Berdasarkan hasil pre-survey peneliti pada bulan April 2017, di RSUD Jendral Ahmad Yani Metro tahun 2016 yaitu jumlah persalinan 949 orang, dengan tindakan SC 28,24 \% faktor penyebabnya 42,91\% akibat pre eklampsi, 1,26\% akibat eklampsi, 1,11\% akibat Infeksi, 11,94\% akibat ketuban pecah dini, 16,41\% akibat perdarahan.

Hasil wawancara didapatkan data dari ibu pasca sectio caesarea, ibu mengatakan nyeri mulai terasa ketika obat bius (anestesi) hilang, nyeri yang hebat 
saat bergerak, nyeri terasa seperti tersayatsayat , ditusuk-tusuk, nyeri dirasakan daerah luka insisi. ibu mengatakan untuk mengurangi rasa nyeri dengan cara beristirahat dan melakukan tarik napas dalam yang sudah diajarkan oleh bidan. Hasil wawancara peneliti pada bidan diruang bersalin untuk mengurangi rasa nyeri pada pasien post operasi sectio caesarea diberikan obat analgetik Keterolac Thromethanine $30 \mathrm{mg}$ dalam Ringer Laktat $500 \mathrm{mg} / 8$ jam atau diberikan obat sub suprafenid $/ 8$ jam. Selain obat analgetik di ajarkan mobilisasi untuk mempercepat penyembuhan luka insisi.

Penelitian Rohmi (2014), yang meneliti tentang "Pengaruh Terapi Murottal Al-Qur'an Terhadap Penurunan Intensitas Nyeri Dan Kecemasan Persalinan Primigrvida Kala 1 Fase Aktif di RSUD Prof. DR. Margono Soekardjo Tahun 2014". Hasil penelitian ada perbedaan yang signifikan pada intensitas nyeri sebelum terapi murrotal adalah 6,57. Rata-rata setelah dilakukan terapi murrotal adalah 4,93. Hasil analisis perbedaan $M=$ 1,643 dan perbedaan $S D=0,821$ $(p=0,000)$. Maka dapat disimpulkan bahwa terdapat perbedaan signifikan skala nyeri sebelum dan sesudah dilakukan terapi murottal. Dengan demikian dapat disimpulkan bahwa pemberian distraksi murrotal Al-Qur'an efektif menurunkan intensitas nyeri persalinan kala 1.

\section{METODE}

Jenis penelitian ini adalah penelitian kuantitatif, desain penelitian ini menggunakan Quasi Experiment, rancangan penelitian menggunakan non equivalentwith Control Group. Populasi dalam penelitian ini adalah seluruh ibu yang menjalani persalinan operasi Sectio Caesarea (SC) setelah 6 jam operasi dan dirawat. Teknik pengambilan sampel yang digunakan adalah dengan menggunakan cara accidental sampling dengan pengambilan sampel untuk masing-masing kelompok adalah 10 kelompok untuk kelompok perlakuan dan 10 kelompok untuk kelompok kontrol.

Penelitian ini terdiri dari dua variabel yaitu variabel bebas (independent) dan variabel terikat (dependent). Menilai intensitas nyeri peneliti menggunakan alat ukur (instrumen) lembar NRS dengan rentang skala nyeri 0-10. Alat yang digunakan Mp3 dan headset yang berisi murrotal Al-Qur'an Surat Al-Kahf dengan qori Muhammad Taha Al-Junayd. Bahan untuk penilaian respon intensitas nyeri yang dipilih yaitu menggunakan skala penilaian Numerical rating scale, (NRS) dengan menggunakan skala 0-10. Teknik pengumpulan data pada penelitian ini yaitu peneliti bersama responden mengisi lembar numeric scale rating pada responden post sectio caesarea setelah 6 jam post operasi, melakukan penilaian intensitas nyeri pada responden yang telah 3 jam diberikan analgetik sesuai standar tindakan.

Kemudian peneliti melakukan terapi murrotal Al-Qur'an selama 15 menit pada kelompok perlakuan, setelah itu peneliti mengkaji ulang intensitas nyeri responden dengan lembar numeric scale rating. Terapi murrotal Al-Qur'an pada kelompok perlakuan dilakukan 2 kali dalam rentang waktu 30 menit kemudian. Pada kelompok kontrol peneliti bersama responden mengisi lembar numeric scale rating pada responden post sectio caesarea setelah 6 jam post operasi, melakukan penilaian intensitas nyeri pada responden yang telah 3 jam diberikan analgetik sesuai standar tindakan. Penilaian intensitas nyeri pada kelompok kontrol dilakukan pretest dan posttest dalam rentang waktu 30 menit kemudian.

Hasil uji normalitas data menggunakan metode analitik parameter Shapiro-Wilk hasil data abnormal, sehingga analisis data menggunakan uji non parametrik Uji Wilcoxon dan Uji Mann-Withney. 
HASIL

\section{Analisis Univariat}

Tabel 1: Distribusi Rata-rata Intensitas Nyeri Sebelum dan Sesudah Diberikan Terapi Murottal AlQur'an pada Kelompok Intervensi

\begin{tabular}{lcccc}
\hline Intensitas & \multicolumn{4}{c}{ Nyeri post Sectio Caesarea } \\
\cline { 2 - 5 } Nyeri & Mean & Med & SD & Min-Max \\
\hline Sebelum & 6.82 & 7.00 & 0.603 & $6-8$ \\
\hline Sesudah & 3.55 & 3.00 & 0.688 & $3-5$ \\
\hline
\end{tabular}

Dari tabel di atas didapatkan bahwa hasil pengukuran rata-rata intensitas nyeri pada pasien post operasi SC sebelum diberikan terapi murottal Al-Qur'an pada kelompok perlakuan adalah mean 6.82 dengan standar deviasi 0.603 , derajat nyeri terendah adalah 6 dan derajat nyeri tertinggi adalah 8. Pengukuran rata-rata intensitas nyeri pada pasien post operasi SC sesudah diberikan terapi murottal AlQur'an kelompok perlakuan adalah mean 3.55 dengan standar deviasi 0.688 , derajat nyeri terendah adalah 3 dan derajat nyeri tertinggi adalah 5 .

Tabel 2: Distribusi Rata-rata Intensitas Nyeri Sebelum dan Sesudah Diberikan Terapi Murottal AlQur'an pada Kelompok Kontrol

\begin{tabular}{ccccc}
\hline Intensitas & \multicolumn{4}{c}{ Nyeri post Sectio Caesarea } \\
\cline { 2 - 5 } Nyeri & Mean & Med & SD & Min-Max \\
\hline Sebelum & 6.64 & 7.00 & 0.674 & $6-8$ \\
\hline Sesudah & 4.91 & 5.00 & 0.701 & $4-6$ \\
\hline
\end{tabular}

Dari tabel di atas didapatkan bahwa hasil pengukuran rata-rata intensitas nyeri pada pasien post operasi SC sebelum diberikan terapi murottal Al-Qur'an pada kelompok kontrol adalah mean 6.64 dengan standar deviasi 0.674 , derajat nyeri terendah adalah 6 dan derajat nyeri tertinggi adalah 8. Pengukuran rata-rata intensitas nyeri pada pasien post operasi SC sesudah diberikan terapi murottal AlQur'an pada kelompok kontrol adalah mean 4.91 dengan standar deviasi 0.701, derajat nyeri terendah adalah 4 dan derajat nyeri tertinggi adalah 6 .

\section{Analisis Bivariat}

Tabel 3: Distribusi Analisis Perbedaan Intensitas Nyeri Sebelum dan Sesudah Diberikan Terapi Murottal Al-Qur'an pada Kelompok Perlakuan dan Kelompok Kontrol

\begin{tabular}{lccc}
\hline \multirow{2}{*}{ Kelompok } & \multicolumn{3}{c}{ Nyeri post Sectio Caesarea } \\
\cline { 2 - 4 } & Mean & SD & p-value \\
\hline Kontrol & 1.73 & 0.647 & 0.003 \\
\hline Intervensi & 3.27 & 0.457 & 0.002 \\
\hline
\end{tabular}

Berdasarkan tabel di atas, perbedaan selisih penurunan intensitas nyeri pada pasien post operasi SC sebelum dan sesudah diberikan murottal Al-Qur'an pada kelompok perlakuan adalah mean 3.27 dengan standar deviasi 0.457 dan perbedaan selisih penurunan intensitas nyeri pada pasien post operasi SC sebelum dan sesudah diberikan murottal Al-Qur'an pada kelompok kontrol adalah mean 1.73 dengan standar deviasi 0.647. Hasil uji Wilcoxon kelompok perlakuan didapatkan $p$-value 0.002 ( $p$-value < 0.05) yang artinya ada perbedaan penurunan intensitas nyeri pada pasien post operasi SC sebelum dan sesudah diperdengarkan murottal pada kelompok perlakuan, sedangkan kelompok kontrol didapatkan $p$-value 0.003 ( $p$-value $<0.05$ ) yang artinya ada perbedaan penurunan intensitas nyeri pada pasien post operasi SC sebelum dan sesudah diperdengarkan murottal pada kelompok kontrol.

Tabel 4: Distribusi Analisis Perbedaan Pengaruh Terapi Murottal AlQur'an Terhadap Penurunan Intensitas Nyeri pada Kelompok Perlakuan dan Kontrol

\begin{tabular}{cccc}
\hline \multirow{2}{*}{ Kelompok } & \multicolumn{3}{c}{$\begin{array}{c}\text { Nyeri post Sectio } \\
\text { Caesarea }\end{array}$} \\
\cline { 2 - 4 } & $\mathrm{n}$ & Mean & $p$-value \\
\hline Perlakuan-Kontrol & 22 & 1.54 & 0.001 \\
\hline
\end{tabular}


Tabel di atas menunjukkan nilai berdasarkan hasil uji Mann-Withney signifikan sebesar $0.001<0.05$, berarti ada perbedaan signifikan pengukuran data kelompok perlakuan dan kelompok kontrol sehingga dapat diartikan ada perbedaan pengaruh terapi murottal Al-Qur'an terhadap penurunan intensitas nyeri pada pasien post operasi SC pada kelompok perlakuan dan kontrol.

\section{PEMBAHASAN}

Perbedaan Pengaruh Terapi Murrotal Al-Qur'an Terhadap Intensitas Nyeri Pada Pasien Post Operasi Sectio Caesarea (SC) Pada Kelompok Perlakuan Dan Kelompok Kontrol.

P-value 0.001 ( $p$-value $<0.05)$ yang artinya ada perbedaan yang signifikan pengaruh terapi murottal Al-Qur'an terhadap penurunan intensitas nyeri pada pasien post operasi sectio caesarea pada kelompok perlakuan dan kontrol.

Kelompok perlakuan dari penelitian ini mendapatkan terapi standar analgetik dan diberikan terapi murottal Al-Qur'an Mekanisme murottal menurunkan nyeri sebagaimana dijelaskan dalam teori Gate Control dimana impuls musik (murottal) yang berkompetisi mencapai korteks serebri bersamaan dengan impuls nyeri akan berefek pada distraksi kognitif dalam inhibisi persepsi nyeri (Potter \& Perry, 2010). Murottal merupakan salah satu musik yang memiliki pengaruh positif bagi pendengarnya (Widayarti, 2011).

Al-Qur'an mengandung kualitas nada huruf yang bervariasi yang dipadukan oleh Allah SWT., sehingga bila dibaca akan terasa keindahnya. Oleh karena itu Al-Qur'an bila dibaca dengan baik dan benar, maka akan memberikan efek sebagaimana musik dan lagu. Susunan huruf, kata-kata dan bunyi huruf Al-Qur'an sesuai dengan susunan syaraf dalam tubuh manusia sehingga setiap bunyi huruf Al-Qur'an yang dilontarkan akan direspon secara positif oleh urat syaraf. Gelombang alunan nada-nadanya amat indah dan selalu menyita perhatian pendengar, tak seorang pun yang mampu memebuat sastra yang keindahan dan keteraturan melebihi Al-Qur'an (Elzaky, 2014).

Karakteristik surah Al-Kahf yang dilantunkan oleh Muhammad Taha AlJunayd mempunyai timbre medium, pitch $44 \mathrm{~Hz}$, harmony regular dan consistent, rhythm andate (mendayu-dayu), volume 50 decibel, intensitas medium amplitude. Pada pitch yang rendah dengan rythm yang lambat dan volume yang rendah akan menimbulkan efek rileks. Frekuensi yang telah terbukti untuk mengurangi nyeri pasca operasi dan menimbulkan efek tenang adalah 40-60 Db. Sedangkan waktu yang dibutuhkan dalam auditoris therapy (terapi pendengaran) supaya dapat memberikan efek terapeutik adalah minimal selama 15 menit (Wirakhmi, 2016).

Mendengarkan Al-Qur'an akan memberikan efek ketenangan dalam tubuh sebab adanya unsur meditasi autosugesti dan relaksasi. Rasa tenang ini akan memberikan respon emosi postif yang sangat berpengaruh dalam mendatangkan persepsi positif. Persepsi positif yang didapat dari murrotal selanjutnya akan merangsang hipotalamus untuk mengeluarkan hormone endorphin, selanjutnya amigdala akan merangsang pengktifan sekaligus pengendalian saraf otonom yang terdiri dari saraf simpatis dan parasimpatis. Saraf simpatis berfungsi untuk mempersarafi jantung dan memperlambat denyut jantung, sedangkan saraf parasimpatis sebaliknya. Rangsangan saraf otonom yang terkendali akan menyebabkan sekresi epinefrin dan norepinefrin akan menghambat pembentukan angiotensin yang selanjutnya dapat menurunkan darah (Wirakhmi, 2016).

Sesuai dengan teori gate control yang dikemukakan oleh Melzack dan Wall bahwa impuls nyeri dihambat saat sebuah pertahanan ditutup, sehingga dapat menurunkan intensitas nyeri yang dirasakan. Hal ini menyatakan bahwa distraksi akan merangsang keluarnya hormone enfekalin, serotonin dan 
endorphin. Enfekalin dianggap dapat menimbulkan hambatan presinaptik dan hambatan pasca sinaptik pada serabutserabut nyeri tipe $\mathrm{C}$ dan tipe delta $\mathrm{A}$ dimana mereka bersinaps di komu dorsalis. Proses tersebut mencapai inhibisi dengan penghambatan saluran kalsium. Penghambatan nyeri tersebut yaitu dengan memblok reseptor nyeri sehingga nyeri tidak dikirim ke korteks selebri dan selanjutnya akan menurunkan persepsi nyeri.

Suatu keseimbangan aktivitas dari neuron sensori dan serabut kontrol desenden dari otak mengatur proses pertahanan. Neuron delta-A dan $\mathrm{C}$ melepaskan substansi $\mathrm{P}$ untuk mentransmisi impuls melalui mekanisme pertahanan. Selain itu, terdapat mekanoreseptor, neuron beta-A yang lebih tebal, yang lebih cepat yang melepaskan neurotransmitter penghambat. Apabila masukan yang dominan berasal dari serabut beta-A, akan menutup mekanisme pertahanan.

Mekanisme pentupan ini diyakini dapat terlihat saat seorang perawat menggosok punggung klien dengan lembut. Pesan yang dihasilkan akan menstimulasi mekanoroseptor, apabila masukan yang dominan berasal dari serabt delta-A dan serabut $\mathrm{C}$ maka akan memebuka pertahanan tersebut dank lien mempersepsikan sensasi nyeri. Bahkan, jika impuls nyeri dihantarkan ke otak, terdapat pusat kortek yang lebih tinggi di otak yang memodifikasi nyeri. Alur saraf desenden melepaskan opiate endogen, seperti endorphine dan dinorfin, suatu pembunuh nyeri alami yang berasal dari tubuh. Neuromedulator ini menutup mekanisme pertahanan dengan menghambat pelepasan substansi $P$. Teknik distraksi merupakan upaya untuk melepaskan endorphine (Potter \&Perry, 2006).

Pada penelitian sesuai dengan keadaan di Ruangan Bersalin RSUD Jendral Ahmad Yani Metro, beberapa responden mengeluh sangat nyeri karena baru pertama kali melakukan SC dan pertama kali merasakan nyeri hebat seperti ini. Rata-rata usia yang lebih muda merasakan nyeri nya lebih besar dibandingkan dengan usianya lebih tua. Hal itu karena intensitas nyeri dapat dipengaruhi oleh beberapa faktor seperti usia dan kebudayaan.

Penelitian Wirakhmi

Pengaruh Terapi Murotal Ar Rahman Pada Pasien Pasca Operasi Sectio Caesarea Di RSUD Dr. R. Goeteng Tarunadibrat Purbalingga. Hasil penelitian menunjukkan ada perbedaan bermakna tekanan darah antara sebelum dan sesudah perlakuan pada kedua kelompok ( $p$ sistole 0,003; $p$ diastole 0,018 ), tetapi frekuensi nadi dan pernapasan tidak menujukkan perbedaan bermakna dengan nilai $p$ berurutan $(0,429 ; 0,666)$. Disimpulkan bahwa ada pengaruh murotal Ar Rahman terhadap penurunan tekanan darah pasien pasca operasi sectio caesarea tetapi tidak demikian pada penurunan frekuensi nadi dan pernapasan.

Penelitian Yusnita (2013) Pengaruh Terapi Musik Manajemen Nyeri Pada Post Operasi Sectio Caesarea Di Ruang Delima RSUD Pasar Rebo. Hasil penelitian $(P$ value $=0,002 ; a=0,05)$. Ada pengaruh terapi musik terhadap manajemen nyeri pada pasien post operasi Sectio Caesarea

Dari pembahasan di atas dapat disimpulkan bahwa ada pengaruh murottal Al-Qur'an terhadap penurunan intensitas nyeri pada pasien post operasi SC di Ruang Bersalin RSUD Jendral Ahmad Yani Metro. Perbedaan ini terjadi karena setelah diperdengarkan murottal AlQur'an terjadi penurunan derajat intensitas nyeri dengan tidak diperdengarkan AlQur'an adalah mean 1.54 . Murottal AlQur'an merupakan salah satu teknik distraksi non medis yang dapat memperbaiki intensitas nyeri pada pasien post operasi SC.

\section{KESIMPULAN}

Berdasarkan hasil penelitian ini dapat disimpulkan bahwa terdapat perbedaan intensitas nyeri sebelum dan 
sesudah diberikan terapi murrotal pada kelompok perlakuan ( $p$-value 0.002) dan terdapat perbedaan penurunan intensitas nyeri sebelum dan sesudah diberikan terapi murrotal pada kelompok control ( $p$ value 0.003 ).

Hasil analisis perbedaan pada keloman kontrol disimpulkan bahwa terdapat perbedaan selisih rata-rata intensitas nyeri pada kelompok kontrol dan kelompok perlakuan ( $p$-value 0.001), sehingga dapat disimpulkan bahwa ada perbedaan pengaruh terapi murrotal AlQur'an terhadap penurunan intensitas nyeri pada pasien post operasi SC pada kelompok kontrol dan kelompok perlakuan. Berdasarkan angka penurunan dan nilai $p$-value, maka dapat disimpulkan bahwa terapi al-qur'an lebih efektif menurunkan nyeri pada pasien post operasi SC.

\section{DAFTAR PUSTAKA}

Elzaky, Jamal. 2010. Buku Saku Terapi Baca Al-Qur'an. Kairo: Syuruq.

Potter \& Perry. 2010. Fundamental of Nursing, Fundamental Keperawatan Buku 2 Edisi 7. Jakarta: Salemba Medika.

2006. Buku Ajar Fundamental Keperawatan Konsep, Proses, dan Praktik Edisi 4. Jakarta: EGC.

Wirakhmi, Ikit Netra \& Hikmanti, Arlyana. 2016. Pengaruh Terapi Murrotal Ar-Rahman Pada Pasien Pasca Operasi Sectio Caesarea Di RSUD Dr. R. Goeteng Tarunadibrata Purbalingga. ojs.akbidylpp.ac.id/index.php/Pradal article/viewFile/147/135.

Yusnita, Erna. 2013. Pengaruh Terapi Musik Terhadap Manajemen Nyeri Pada Pasien Post Operasi Sectio Caesarea Di Ruang Delima RSUD Pasar Rebo Tahun 2013. https://ayurvedamedistra.files.wordp ress.com. 